\title{
Molecular Epidemiology of Hepatitis B Virus
}

\author{
Jia-Horng Kao
}

Department of Internal Medicine, Graduate Institute of Clinical Medicine, Hepatitis Research Center, and Department of Medical Research, National Taiwan University Hospital, National Taiwan University College of Medicine, Taipei, Taiwan

Although safe and effective vaccines for hepatitis B virus (HBV) have been available for nearly three decades, this virus kills at least 600,000 people annually worldwide and remains the leading global cause of chronic hepatitis, cirrhosis, and hepatocellular carcinoma. Because the HBV reverse transcriptase lacks a proofreading function, many HBV genotypes, subgenotypes, mutants, and recombinants exist. At least $10 \mathrm{HBV}$ genotypes (HBV-A through J) with distinct geographic distributions have been identified; by definition, their complete genomic sequences diverge by more than $8 \%$. HBV genotype is increasingly becoming recognized as an important factor in the progression and clinical outcome of HBVinduced disease. Infections by HBV-C or -D are significantly more likely to lead to cirrhosis and hepatocellular carcinoma than are infections by HBV-A or -B. Additionally, the hepatitis B e antigen seroconversion response to standard or pegylated interferon is more favorable in patients with HBV-A or -B than in those with HBV-C or -D. However, therapeutic responses to nucleos(t)ide analogues are generally comparable among HBV genotypes. In conclusion, genotyping of $\mathrm{HBV}$ is useful in identifying chronic hepatitis B patients who are at increased risk of disease progression, thereby enabling physicians to optimize antiviral therapy for these patients.

Keywords: Antiviral agents; Genotype; Hepatitis B virus; Hepatocellular carcinoma; Molecular epidemiology

\section{INTRODUCTION}

Although safe and effective vaccines for hepatitis B virus (HBV) have been available for more than two decades, infection by this organism remains a burden to global public health, resulting in 600,000 to 1 million deaths per year worldwide [1]. Clinically, HBV infection can manifest in acute/fulminant hepatitis or in various chronic conditions, including an inactive carrier state, chronic hepatitis, cirrhosis, and hepatocellular carcinoma (HCC) [2]. Approximately $15-40 \%$ of $\mathrm{HBV}$ carriers who acquire the virus early in life eventually develop HBV-related cirrhosis or HCC [3].

Being a virus of the family Hepadnaviridae, HBV is the smallest human DNA virus, carrying a genome only 3,200 nucleotides in length [4]. The partially double-stranded circular DNA harbors four overlapping open reading frames encoding the $\mathrm{S}$ (surface), $\mathrm{C}$ (core), $\mathrm{P}$ (polymerase), and $\mathrm{X}$ genes (Fig. 1). Because the viral reverse transcriptase has a high error rate, the HBV genome evolves quickly over time, with an estimated nucleotide substitution rate of 1.4-3.2 $\times 10^{-5} /$ site per year [4]. This unique replication strategy accounts for the majority of the point mutations, deletions, and insertions observed in the HBV genome. The lengthy evolution of HBV has led to the present existence of various genotypes, subgenotypes, mutants, recombinants, and even quasispecies of HBV [5]. 


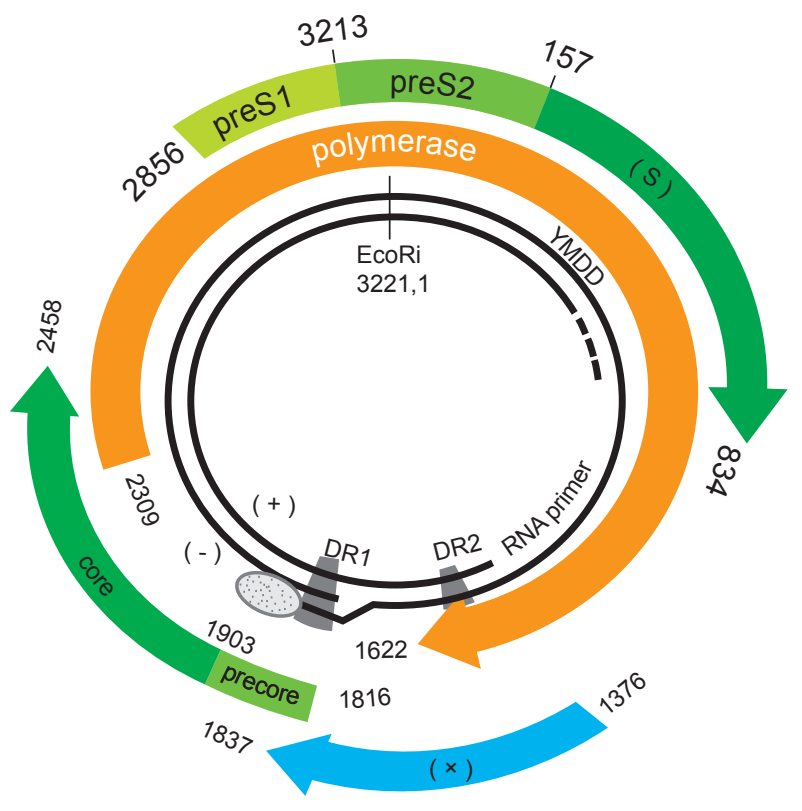

Figure 1. Hepatitis B virus has a partially double-stranded circular DNA genome harboring four overlapping open reading frames: S, surface gene; $\mathrm{C}$, core gene; $\mathrm{P}$, polymerase gene; $\mathrm{X}, \mathrm{X}$ gene.

\section{EPIDEMIOLOGY AND DISEASE PRO- GRESSION OF HBV INFECTION}

HBV is endemic in Asia and the Pacific islands, Africa, Southern Europe, and Latin America. The community prevalence of the HBV surface antigen (HBsAg) encoded by gene $\mathrm{S}$ ranges from 2 to $20 \%$ [1]. In Asian countries, the majority of HBV infections are acquired perinatally or in early childhood by the age of 2 years through vertical (mother-to-child) transmission; however, horizontal transmission is the main route of infection in African and Western countries [1].
Disease progression in patients with chronic hepatitis B varies widely. Several viral factors, including the HBV genotype, viral load, and specific viral mutations, have been documented to be strongly associated with disease progression and outcomes (Table 1). The annual incidence of cirrhosis is estimated to be $2-6 \%$ in those who test positive for the HBV e antigen (HBeAg) and 8-10\% in those who test negative. The annual incidence of HCC is less than $1 \%$ for patients without cirrhosis and $2-3 \%$ for patients with cirrhosis $[2,3]$.

\section{MOLECULAR EPIDEMIOLOGY OF HBV GENOTYPES AND SUBTYPES}

Analyses of the divergence of $\mathrm{HBV}$ genomic sequences has led to the identification of $10 \mathrm{HBV}$ genotypes (A through J) and several subtypes, where separate genotypes and subtypes are defined as strains exhibiting an entire genome sequence divergence of more than $8 \%$ or $4-8 \%$, respectively [6]. The geographic distribution of $\mathrm{HBV}$ genotypes A-H and their subtypes is shown in Table 2. Genotype A is highly prevalent in sub-Saharan Africa (subtype A1), Northern Europe (subtype A2), and Western Africa (subtype A3). Genotypes B and C are prevalent in the Asian Pacific region. However, the prevalence rates of genotypes B and C vary among the different Asian countries (Table 3) [7]. For example, HBV-C is more common than HBV-B in China, Japan, and Korea, whereas HBV-B is the more common genotype in Taiwan and Vietnam [8]. Of particular note is the fact that almost all chronic hepatitis B patients in Korea are infected with HBV-C [7].

Genotype B has six subtypes, B1-B6. B1 is found in Japan; B2-B5 and B7 are found in East Asia, and B6 is found

Table 1. Risk factors associated with disease progression in chronic hepatitis B patients

\begin{tabular}{lll}
\hline Viral factors & Host factors & Environmental factors \\
\hline High viral load & Advanced age & Aflatoxin exposure \\
Genotype (HBV-C > HBV-B; HBV-D > HBV-A) & Male gender & Alcohol consumption \\
Basal core promoter mutation & Genetic alterations & Cigarette smoking \\
Pre-S deletion & Family history of HCC & Concurrent infection with hepatitis C or \\
& Ethnicity (Asian > Caucasian) & D virus or with HIV \\
& & Diabetes mellitus \\
& & Obesity \\
& & Metabolic syndrome
\end{tabular}

HBV, hepatitis B virus; HCC, hepatocellular carcinoma; HIV, human immunodeficiency virus. 
Table 2. Geographic distribution of HBV genotypes and subtypes

\begin{tabular}{lcl}
\hline Genotype & Subtype & \multicolumn{1}{c}{ Geographic location } \\
\hline A & A1 & Sub-Saharan Africa \\
& A2 & Northern Europe \\
& A3 & Western Africa \\
B & B1 & Japan \\
& B2-B5 & $\begin{array}{l}\text { Taiwan, China, Indonesia, Vietnam, } \\
\text { Philippines }\end{array}$ \\
& B6 & Alaska, Northern Canada, Greenland \\
& C1-C3 & $\begin{array}{l}\text { Taiwan, China, Japan, Korea, Southeast } \\
\text { C }\end{array}$ \\
& C4 & Australia \\
& C5 & $\begin{array}{l}\text { Philippines, Vietnam } \\
\text { Africa, Europe, Mediterranean basin, } \\
\text { India }\end{array}$ \\
D & D1-D5 & Restricted to West Africa \\
E & & Central and South America \\
F & F1-F4 & France, Germany, United States \\
G & & Central America \\
H & & Laos, Vietnam \\
I & & Japan \\
J & &
\end{tabular}

Table 3. Distribution of hepatitis B virus (HBV) genotypes in different Asian countries

\begin{tabular}{lrrrrc}
\hline & \multicolumn{5}{c}{ Prevalence (\%) of HBV genotype } \\
\cline { 2 - 6 } Country & A & \multicolumn{1}{c}{ B } & C & D & Others \\
\hline China & 2 & 41 & 53 & 1 & 1 \\
Hong Kong & 0 & 33 & 63 & 0 & 4 \\
Japan & 2 & 12 & 85 & 0 & 1 \\
Korea & 0 & 0 & 100 & 0 & 0 \\
Philippines & 51 & 22 & 27 & 0 & 0 \\
Solomon & 0 & 0 & 55 & 45 & 0 \\
Taiwan & 3 & 71 & 22 & 0 & 4 \\
Thailand & 1 & 12 & 87 & 0 & 0 \\
Vietnam & 22 & 12 & 30 & 24 & 12 \\
\hline
\end{tabular}

in indigenous populations living in Arctic regions, including Alaska, Northern Canada, and Greenland. Genotype $\mathrm{C}$, which has subtypes $\mathrm{C}_{1}-\mathrm{C}_{5}$, is found primarily in East and Southeast Asia. Genotype D, which has subtypes D1D5, is prevalent in Africa, Europe, the Mediterranean region, and India. Genotype E is restricted to West Africa. Genotype F, which has 4 subtypes (F1-F4), is found in Central and South America. Genotype G has been reported in France, Germany, and the United States. Genotype H is found in Central America [9,10]. Recently, genotype I was isolated in Vietnam and Laos [11], and genotype $J$ was identified in Japan [12].

\section{HBV GENOTYPE AND DISEASE PRO- GRESSION IN PATIENTS WITH CHRONIC HEPATITIS B}

Current evidence for the impact of HBV genotype on the short- and long-term adverse outcomes of chronic HBV infection is summarized in Table 4. Most retrospective and case-control studies have indicated that patients infected with HBV-C have more severe liver disease, including cirrhosis and HCC, than those with infected with HBV-B $[2,8,13]$. In a recent community-based prospective cohort study of 2762 Taiwanese HBV carriers, HBV-C was associated with a higher risk of HCC than was HBV-B; the adjusted hazard ratio was 2.35 (95\% confidence interval [CI], 1.68 to 3.30; $p<0.001$ [14]. These findings confirm that HBV-C is associated with a higher risk of HCC development than HBV-B is.

HBV genotype also affects the clinicopathologic features of patients with resectable HCC. Of 193 patients with resectable HBV-related HCC in Taiwan, those infected with HBV-B had a higher rate of solitary tumor than did those infected with HBV-C (94\% vs. 86\%; $p=0.048$ ), but they also had more satellite nodules ( $22 \%$ vs. $12 \% ; p=0.05$ ). These features may contribute to the recurrence patterns and prognosis of HBV-related HCC patients infected with HBV-B or -C infection $[15,16]$. Death related to liver disease occurs more often in patients with HBV-D and -F than in those with HBV-A [17,18].

The importance of HBV genotype on the development of HCC has prompted the recent development of a clinical HBV scoring system, a nomogram including several independent risk predictors, including sex, age, family history of HCC, alcohol consumption, serum alanine aminotransferase (ALT) level, HBeAg status, serum HBV DNA level, and HBV genotype [19]. Based on clinical characteristics that can be determined noninvasively, this easy-to-use nomogram has been found to accurately predict HCC risk in HBV-infected persons and could facilitate communication between physicians and their patients, particularly in the Asian Pacific region. 
Table 4. Associations between hepatitis B virus (HBV) genotypes and markers of disease progression in patients with chronic HBV infection

\begin{tabular}{|c|c|c|c|c|}
\hline \multirow[t]{2}{*}{ Genotypes compared } & \multicolumn{2}{|c|}{ B vs. $C^{a}$} & \multicolumn{2}{|c|}{ A vs. $D^{a}$} \\
\hline & $\mathrm{B}$ & $\mathrm{C}$ & A & $\mathrm{D}$ \\
\hline Timing of HBeAg seroconversion & Earlier & Later & Earlier & Later \\
\hline Incidence of HBsAg seroclearance & Higher & Lower & Higher & Lower \\
\hline Severity of liver histology & Lower & Higher & Lower & Higher \\
\hline $\begin{array}{l}\text { Incidence of progression to cirrhosis and } \\
\text { hepatocellular carcinoma }\end{array}$ & Lower & Higher & Lower & Higher \\
\hline
\end{tabular}

HBeAg, HBV e-antigen; HBsAg, HBV surface antigen.

${ }^{a}$ Because of the unique distribution of HBV genotypes in Asian and Western countries, sufficient data for meaningful comparisons are available only for comparisons between genotypes $B$ and $C$ or betweens genotype $A$ and $D$.

\section{MOLECULAR MECHANISMS OF HBV GENOTYPE-SPECIFIC PATHOGENESIS}

The pathogenic differences among various HBV genotypes have been partially clarified. Intracellular expression levels of HBV DNA and HBV core antigen ( $\mathrm{HBcAg}$ ), as well as the extracellular levels of HBV DNA and HBeAg, have been found to be higher for HBV-B and -C genotypes than for HBV-A and -D. The intracellular accumulation of HBV DNA and viral antigens may play a role in inducing liver cell damage. Additionally, the higher replication capacity of the $\mathrm{C}$ genotype may explain why it is the genotype associated with the most severe HBV-induced liver disease [20,21].

In recent in vitro studies, we found that; 1) the expression of intracellular HBV core protein increased in strains of the $\mathrm{C}$ genotype when mutations were made in the precore or basal core promoter regions affecting HBeAg expression; 2) the expression of intracellular HBV surface protein was lower for a precore wild-type HBV-C strain than for HBV-B; 3) the precore mutation was associated with a decreased level of extracellular HBV DNA; 4) less HBsAg was secreted by HBV-C than by HBV-B; and 5) less HBeAg was secreted by HBV-B than by HBV-C [22]. The in vivo and in vitro manifestations of HBV-B and $-\mathrm{C}$ are compared in Table 5 .

\section{HBV GENOTYPE AND ANTI-VIRAL TREATMENTS}

\section{Interferon-based therapy}

The therapeutic endpoints for the management of chronic hepatitis B include sustained suppression of the HBV DNA level, normalization of the serum ALT level, histologic improvement, HBeAg clearance or seroconversion (for HBeAg-positive patients), and HBsAg clearance or seroconversion [23]. Two types of drug therapy are in current use for HBV treatment: interferon (IFN)- $\alpha$, which is used in both standard and pegylated forms, and nucleos(t)ide analogues, including lamivudine, telbivudine, entecavir, adefovir dipivoxil, and tenofovir disoproxil furamate [6-8].

Recent studies have suggested that HBV genotype affects the therapeutic response to both IFN and nucleos(t)ide analogue-based agents [23,24]. In brief, the incidence of sustained ALT normalization and HBeAg seroconversion 6-12 months after the cessation of interferon treatment is significantly higher in patients with HBV-A and -B than in those with HBV-C or -D [25,26]. In Asian HBeAgpositive patients, those with HBV-B are susceptible to both standard and pegylated IFN, and those with HBV-C are more likely to respond favorably to pegylated IFN than to standard IFN [27-31]. Additionally, the incidence of durable HBeAg clearance 3 years after the cessation of pegylated IFN-a treatment is higher in patients with HBV-A or -B than in those with HBV-C or -D [32].

In the absence of a cure for chronic HBV infection, the desired endpoint in current management of this disease is the complete suppression of HBsAg expression. In a longterm follow-up study of HBeAg-negative patients treated with pegylated IFN, patients infected with HBV-A had a significantly higher mean incidence of HBsAg clearance (20\%) than those infected with HBV-B, -C, or -D (mean clearance rates of 6,9 , and $6 \%$, respectively) [33]. Additionally, the kinetics of HBsAg clearance during pegylated 
Table 5. In vivo and in vitro manifestations of HBV-B vs. HBV-C

\begin{tabular}{|c|c|c|c|}
\hline & In vivo & In vitro & Implications \\
\hline \multirow[t]{2}{*}{$\mathrm{HBeAg}$} & $\begin{array}{l}\text { Longer immune clearance phase } \\
\text { (in HBeAg-positive patients) for } \\
\text { HBV-C }\end{array}$ & $\begin{array}{l}\text { More HBeAg secreted for } \\
\text { HBV-C }\end{array}$ & $\begin{array}{l}\text { Increased secretion of } \mathrm{HBeAg} \text { in } \\
\mathrm{HBV}-\mathrm{C} \text { leads to a longer immune } \\
\text { clearance phase for HBV-C }\end{array}$ \\
\hline & $\begin{array}{l}\text { Earlier HBeAg seroconversion for } \\
\text { HBV-B }\end{array}$ & & \\
\hline HBsAg & Higher HBsAg titer for HBV-B & $\begin{array}{l}\text { More HBsAg secreted for } \\
\text { HBV-B }\end{array}$ & $\begin{array}{l}\text { Findings are consistent, but biological } \\
\text { and clinical significance remain to } \\
\text { be clarified }\end{array}$ \\
\hline $\begin{array}{l}\text { Hepatitis flare after } \\
\text { spontaneous HBeAg } \\
\text { loss }\end{array}$ & More frequent for HBV-C & $\begin{array}{l}\text { Increased expression of } \\
\text { intracellular core protein when } \\
\text { precore or BCP mutation } \\
\text { introduced into HBV-C }\end{array}$ & $\begin{array}{l}\text { Increased expression of core protein } \\
\text { on hepatocyte membrane in HBV-C } \\
\text { triggers more immune-mediated } \\
\text { hepatocytolysis }\end{array}$ \\
\hline Serum HBV DNA level & $\begin{array}{l}\text { Comparable between HBV-B and } \\
\text { HBeAg-positive HBV-C }\end{array}$ & $\begin{array}{l}\text { Extracellular HBV DNA levels } \\
\text { similar }\end{array}$ & $\begin{array}{l}\text { Wild-type HBV-B and -C have similar } \\
\text { replication efficiency }\end{array}$ \\
\hline
\end{tabular}

HBV, hepatitis B virus; HBeAg, HBV e-antigen; HBsAg, HBV surface antigen; BCP, basal core promoter.

IFN treatment varied among the different $\mathrm{HBV}$ genotypes. For example, at the end of treatment, the mean decline in HBsAg levels was greatest in patients with HBV-A, intermediate in those with HBV-B or -D, and least in those with HBV-C or -E; during the follow-up period, the serum HBsAg level continued to decrease in the patients with HBVA or $-\mathrm{D}$, whereas HBsAg rebound was observed in those with HBV-B, -C, or -E [34].

A recent meta-analysis confirmed that patients infected with HBV-A respond better to IFN- $\alpha$ treatment than do those infected with HBV-D, regardless of the patient's HBeAg status, and that HBeAg-positive patients infected with HBV-B respond better to IFN- $\alpha$ treatment than do HBeAg-positive patients infected with HBV-C [35]. Therefore, patients with HBV-A or -B infection generally have a better response to IFN- $\alpha$ than do those with HBV-C or -D infection [36]. The data pooled from the two largest global trials of HBeAg-positive patients treated with pegylated IFN demonstrate that HBV-A patients with a higher ALT level or a lower HBV DNA level and HBV-B and -C patients with both a higher ALT level and a lower HBV DNA level have a high predicted probability of a sustained response and should be considered for IFN therapy. On the other hand, HBV-D patients have the lowest chance of sustained response, irrespective of their ALT or HBV DNA levels; IFN therapy is thus not recommended for these patients [37].

\section{Therapy with nucleoside or nucleotide analogues}

In most clinical studies, the therapeutic responses to lamivudine, adefovir, entecavir, and telbivudine have been similar among the different HBV genotypes [5,8,23,24], and a recent meta-analysis found no significant association between $\mathrm{HBV}$ genotype and the response to nucleos(t)ide analogues [35]. Although HBV genotypes seem to have little impact on the response to nucleos(t)ide analogue treatment [36], our retrospective analysis has suggested that genotype B is independently associated with earlier detection of lamivudine resistance. Additionally, we found that the development of lamivudine resistance within the first 12 months of lamivudine therapy had a significantly higher association with genotype $B$ than with genotype $\mathrm{C}$ (odds ratio, 8.27; $p=0.004$ ) [38]. Therefore, more fre quent monitoring of genotypic resistance might be needed for specific HBV genotypes during nucleos(t)ide analogue therapy.

Complete clearance of HBsAg is rare in chronic hepatitis B patients treated with oral agents. However, Marcellin et al. [39] recently reported that complete HBsAg clearance occurred in five of $158 \mathrm{HBeAg}$-positive patients after 48 weeks of treatment with tenofovir disoproxil. Of these five Caucasian patients, two were infected with HBV-A, and three were infected with HBV-D. Although the proportion of patients with HBsAg loss was too small to reach any definite conclusions, the association of HBV genotype with nucleos(t)ide analogue-induced HBsAg clearance is interesting and deserves further study. 


\section{CONCLUSIONS}

Investigations of the molecular epidemiology and clinical implications of HBV genotypes have resulted in clinically significant advances over the past decade, particularly with regards to genotypes found in the Asian Pacific region. Accumulating evidence [40] suggests that a patient with chronic HBV infection should receive HBV genotyping unless he or she lives in a country known to harbor only one HBV genotype. This measure will help practicing physicians to identify those patients who are at increased risk of disease progression to end-stage liver disease and those who can benefit most from interferon-based therapy [41,42].

\section{Conflict of interest}

No potential conflict of interest relevant to this article was reported.

\section{Acknowledgments}

The study was supported by grants from the National Taiwan University Hospital, the Department of Health, and the National Science Council, Executive Yuan, Taiwan.

\section{REFERENCES}

1. Kao JH, Chen DS. Global control of hepatitis B virus infection. Lancet Infect Dis 2002;2:395-403.

2. Kao JH, Chen PJ, Chen DS. Recent advances in the research of hepatitis B virus-related hepatocellular carcinoma: epidemiologic and molecular biological aspects. Adv Cancer Res 2010;108:21-72.

3. Fattovich G, Bortolotti F, Donato F. Natural history of chronic hepatitis B: special emphasis on disease progression and prognostic factors. J Hepatol 2008;48:335-352.

4. Lau JY, Wright TL. Molecular virology and pathogenesis of hepatitis B. Lancet 1993;342:1335-1340.

5. Kao JH. Hepatitis B viral genotypes: clinical relevance and molecular characteristics. J Gastroenterol Hepatol 2002;17:643650.

6. Kurbanov F, Tanaka Y, Mizokami M. Geographical and genetic diversity of the human hepatitis B virus. Hepatol Res 2010;40:14-30.

7. Lin CL, Kao JH. Hepatitis B viral factors and clinical outcomes of chronic hepatitis B. J Biomed Sci 2008;15:137-145.

8. Lin CL, Kao JH. The clinical implications of hepatitis B virus genotype: Recent advances. J Gastroenterol Hepatol 2011;26 Suppl 1:123-130.

9. Kao JH, Chen DS. HBV genotypes: epidemiology and implications regarding natural history. Curr Hepat Rep 2006;5:5-13.

10. Datta S. An overview of molecular epidemiology of hepatitis B virus (HBV) in India. Virol J 2008;5:156.

11. Phung TB, Alestig E, Nguyen TL, Hannoun C, Lindh M. Genotype $\mathrm{X} / \mathrm{C}$ recombinant (putative genotype $\mathrm{I}$ ) of hepatitis $\mathrm{B}$ virus is rare in Hanoi, Vietnam: genotypes $\mathrm{B} 4$ and $\mathrm{C} 1$ predominate. $\mathrm{J}$ Med Virol 2010;82:1327-1333.

12. Tatematsu K, Tanaka $Y$, Kurbanov F, et al. A genetic variant of hepatitis B virus divergent from known human and ape genotypes isolated from a Japanese patient and provisionally assigned to new genotype J. J Virol 2009;83:10538-10547.

13. McMahon BJ. The influence of hepatitis B virus genotype and subgenotype on the natural history of chronic hepatitis B. Hepatol Int 2009;3:334-342.

14. Yang HI, Yeh SH, Chen PJ, et al. Associations between hepatitis $\mathrm{B}$ virus genotype and mutants and the risk of hepatocellular carcinoma. J Natl Cancer Inst 2008;100:1134-1143.

15. Chen JD, Liu CJ, Lee PH, et al. Hepatitis B genotypes correlate with tumor recurrence after curative resection of hepatocellular carcinoma. Clin Gastroenterol Hepatol 2004;2:64-71.

16. Lin CL, Chen JD, Liu CJ, et al. Clinicopathological differences between hepatitis B viral genotype B- and C-related resectable hepatocellular carcinoma. J Viral Hepat 2007;14:64-69.

17. Sanchez-Tapias JM, Costa J, Mas A, Bruguera M, Rodes J. Influence of hepatitis B virus genotype on the long-term outcome of chronic hepatitis B in western patients. Gastroenterology 2002;123:1848-1856.

18. Livingston SE, Simonetti JP, McMahon BJ, et al. Hepatitis B virus genotypes in Alaska Native people with hepatocellular carcinoma: preponderance of genotype F. J Infect Dis 2007;195:511.

19. Yang HI, Sherman M, Su J, et al. Nomograms for risk of hepatocellular carcinoma in patients with chronic hepatitis B virus infection. J Clin Oncol 2010;28:2437-2444.

20. Sugiyama M, Tanaka Y, Kato T, et al. Influence of hepatitis B virus genotypes on the intra- and extracellular expression of viral DNA and antigens. Hepatology 2006;44:915-924.

21. Liu CJ, Jeng YM, Chen CL, et al. Hepatitis B virus basal core promoter mutation and DNA load correlate with expression of hepatitis B core antigen in patients with chronic hepatitis B. J Infect Dis 2009;199:742-749.

22. Chen RY, Bowden S, Desmond PV, Dean J, Locarnini SA. Effects of interferon alpha therapy on the catalytic domains of the polymerase gene and basal core promoter, precore and core regions of hepatitis B virus. J Gastroenterol Hepatol 2003;18:630637.

23. Liu CJ, Kao JH, Chen DS. Therapeutic implications of hepatitis 
B virus genotypes. Liver Int 2005;25:1097-1107.

24. Liu CJ, Kao JH. Genetic variability of hepatitis B virus and response to antiviral therapy. Antivir Ther 2008;13:613-624.

25. Kao JH, Wu NH, Chen PJ, Lai MY, Chen DS. Hepatitis B genotypes and the response to interferon therapy. J Hepatol 2000;33:998-1002.

26. Erhardt A, Blondin D, Hauck K, et al. Response to interferon alfa is hepatitis B virus genotype dependent: genotype A is more sensitive to interferon than genotype D. Gut 2005;54:10091013 .

27. Cooksley WG, Piratvisuth T, Lee SD, et al. Peginterferon alpha2a (40 kDa): an advance in the treatment of hepatitis B e antigen-positive chronic hepatitis B. J Viral Hepat 2003;10:298305 .

28. Lau GK, Piratvisuth T, Luo KX, et al. Peginterferon Alfa-2a, lamivudine, and the combination for HBeAg-positive chronic hepatitis B. N Engl J Med 2005;352:2682-2695.

29. Zhao H, Kurbanov F, Wan MB, et al. Genotype B and younger patient age associated with better response to low-dose therapy: a trial with pegylated/nonpegylated interferon-alpha-2b for hepatitis B e antigen-positive patients with chronic hepatitis B in China. Clin Infect Dis 2007;44:541-548.

30. Janssen HL, van Zonneveld M, Senturk H, et al. Pegylated interferon alfa-2b alone or in combination with lamivudine for HBeAg-positive chronic hepatitis B: a randomised trial. Lancet 2005;365:123-129.

31. Flink HJ, van Zonneveld M, Hansen BE, et al. Treatment with Peg-interferon alpha-2b for HBeAg-positive chronic hepatitis B: HBsAg loss is associated with HBV genotype. Am J Gastroenterol 2006;101:297-303.

32. Buster EH, Flink HJ, Cakaloglu Y, et al. Sustained HBeAg and HBsAg loss after long-term follow-up of HBeAg-positive patients treated with peginterferon alpha-2b. Gastroenterology
2008;135:459-467.

33. Marcellin P, Bonino F, Lau GK, et al. Sustained response of hepatitis B e antigen-negative patients 3 years after treatment with peginterferon alpha-2a. Gastroenterology 2009;136:21692179.e1-e4.

34. Moucari R, Martinot-Peignoux M, Mackiewicz V, et al. Influence of genotype on hepatitis B surface antigen kinetics in hepatitis B e antigen-negative patients treated with pegylated interferon-alpha2a. Antivir Ther 2009;14:1183-1188.

35. Wiegand J, Hasenclever D, Tillmann HL. Should treatment of hepatitis B depend on hepatitis B virus genotypes? A hypothesis generated from an explorative analysis of published evidence. Antivir Ther 2008;13:211-220.

36. Raimondi S, Maisonneuve P, Bruno S, Mondelli MU. Is response to antiviral treatment influenced by hepatitis B virus genotype? J Hepatol 2010;52:441-449.

37. Buster EH, Hansen BE, Lau GK, et al. Factors that predict response of patients with hepatitis $B$ e antigen-positive chronic hepatitis B to peginterferon-alfa. Gastroenterology 2009;137:2002-2009.

38. Hsieh TH, Tseng TC, Liu CJ, et al. Hepatitis B virus genotype B has an earlier emergence of lamivudine resistance than genotype C. Antivir Ther 2009;14:1157-1163.

39. Marcellin P, Heathcote EJ, Buti M, et al. Tenofovir disoproxil fumarate versus adefovir dipivoxil for chronic hepatitis B. N Engl J Med 2008;359:2442-2455.

40. Kao JH. Role of viral factors in the natural course and therapy of chronic hepatitis B. Hepatol Int 2007;1:415-430.

41. Kao JH. Appropriate use of interferon for treatment of chronic hepatitis B. Hepatol Res 2007;37(s1):S47-S54.

42. Cooksley WG. Do we need to determine viral genotype in treating chronic hepatitis B? J Viral Hepat 2010;17:601-610. 